\title{
TMS Considers MSE Study at Symposium Honoring Morris Cohen
}

During its Fall Meeting in Orlando, Florida, The Metallurgical Society (TMS) held a symposium to honor Morris Cohen (Sere "Metals Socirtie's Honor Morris Cohen" in this issue.) The two half-day sessions held October 7 and 8 featured an opening address by Prof. Cohen and presentations by representatives of the Materials Science and Engineering Study (MSE) commissioned by the National Academies of Sciences and Engineering (NAS/NAE) at the request of the National Research Council. The sessions were organized by the TMS Governmental, Energy, and Minerals Committee and chaired by the two MSE Study Chairs, Merton Flemings (Massachusetts Institute of Technology) and Praveen Chaudhari (IBM).

\section{Cohen's Address}

After brief introductory remarks by Flemings, Prof. Cohen of MIT reviewed materials science and engineering history since the COSMAT study sponsored by NAS over a decade ago. Prof. Cohen's remarks placed the study of materials within the contexts of the disciplines of science and engineering, and of today's societal and economic realities. Enumerating the five most important resources of mankind today, he included "materials" among those of living space, food, energy and knowledge. He went further to demonstrate that materials science and engineering (MSE) is really a dynamic partnership between basic science and societal needs and experience, with information flowing from these extremes to the mixture called MSE, where structure, property, performance and processing relationships are researched and developed. The unique blending of scientific knowledge and empirical knowledge makes MSE a central function of technical progress today, he said, and pointed out that such a relationship [of MSE to basic science and to society]

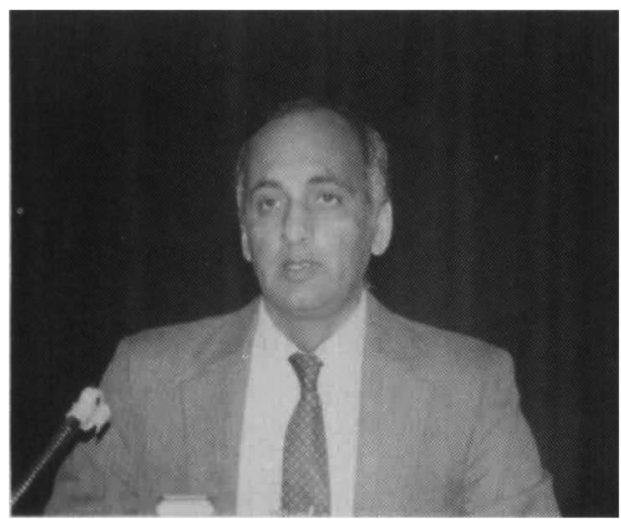

P. Chaudhari, MSE Study Chair.

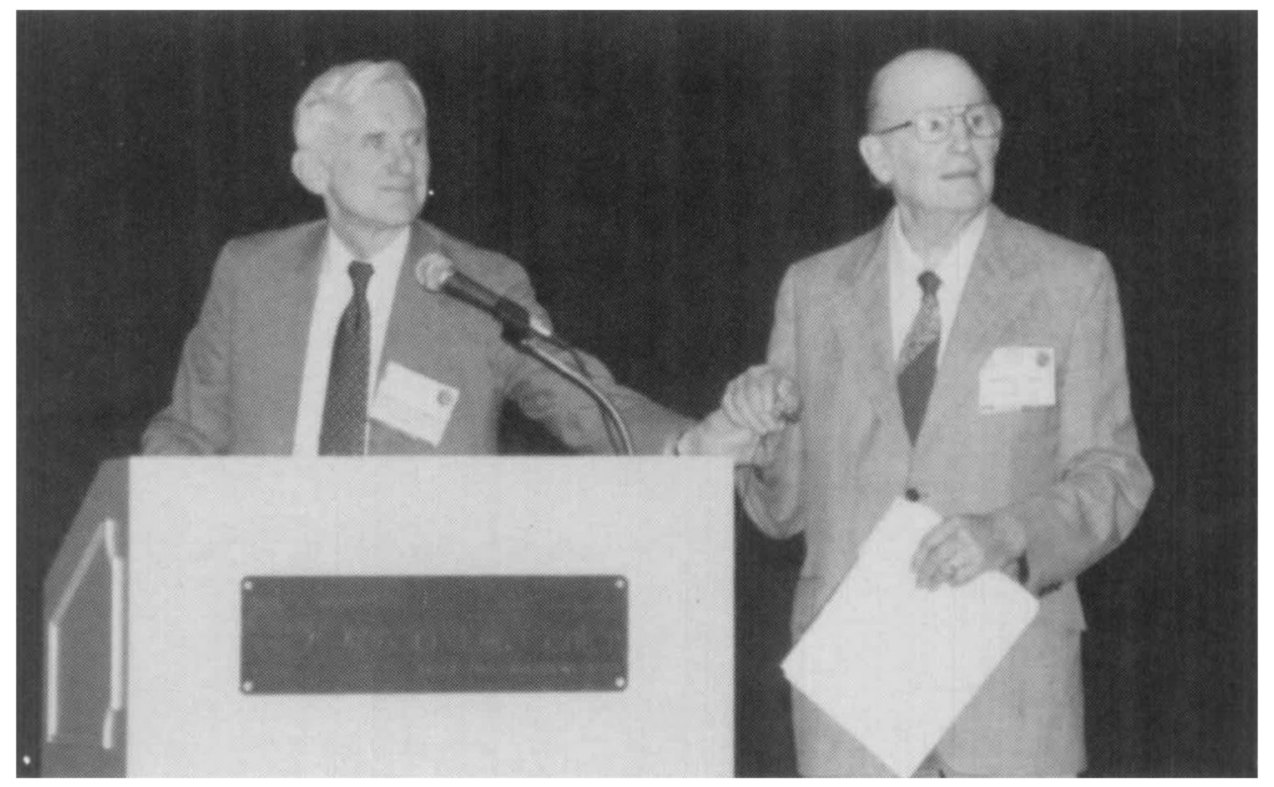

M. Flemings, MSE Study Chair (left), and Morris Cohen (MIT).

necessarily causes it to be mutidisciplinary.

He expounded on the science and engineering disciplines which collaborate in the pursuit of MSE and pointed to the microcosm of this phenomenon represented by metallurgy. Metallurgy was first considered to be multidisciplinary, including, for example, physics, chemistry, chemical engineering and mechanical engineering. It has evolved to where it is considered a single discipline. Cohen questioned the future of MSE-i.e., would it also evolve to being viewed as a single discipline. He drew an analogy to medicine, which is considered a single discipline and rests on a basic common medical curriculum, but at the advanced level is made up of a wide variety of disparate specialties.

Cohen remarked that the term "multidisciplinary" came into vogue following World War II and that the advent of block grants to interdisciplinary centers, beginning with DARPA's (Defense Advanced Research Projects Agency) interdisciplinary laboratories, marked the beginning of local administration of such funds, without individual projects specified by sponsoring agencies. Cohen further noted that the COSMAT study was the first sponsored by NASINAE which involved both science and engineering disciplines. One of the results of the study published in 1974 was the recognition that the panels could not establish a boundary between materials science and materials engineering, and the conclusion that the reference must be to one field-MSE.

MSE Study Chair M. Flemings provided an overview of the current MSE Study, indicating that its five panels are now complete with about 100 panel members actively pursuing their tasks. (Se list of chnirs and panelists on previous page.) He pointed out that, after considerable deliberation, the definition of "materials science and engineering" remains essentially that used by the COSMAT study over a decade ago, except that the phrase "synthesis" has been added to processing, structure, properties and performance of materials.

\section{MSE Study Panel 1}

Describing the mission and status of Panel 1 on Materials Research Opportunities and Needs, Flemings listed several areas in which small workshops will be held, including synthesis, processing, characterization, performance, disordered materials, deliberately structured materials, electronic/photonic materials, structural materials, biomaterials, and computation in MSE. These areas will concentrate on questions and answers regarding research opportunities. Panel 1 subgroups will investigate the following eight industrial needs areas: aerospace, automotive, biomaterial, chemical, communications, electronic, energy, and metals needs. In addition, a separate subgroup of Panel 1 will investigate the federal role in three issues: (1) the transfer of research to missionrelated products and procedures, (2) the need for new materials in areas such as defense, and (3) an identification of the barriers to obtaining new materials for the federal sector.

Continued 


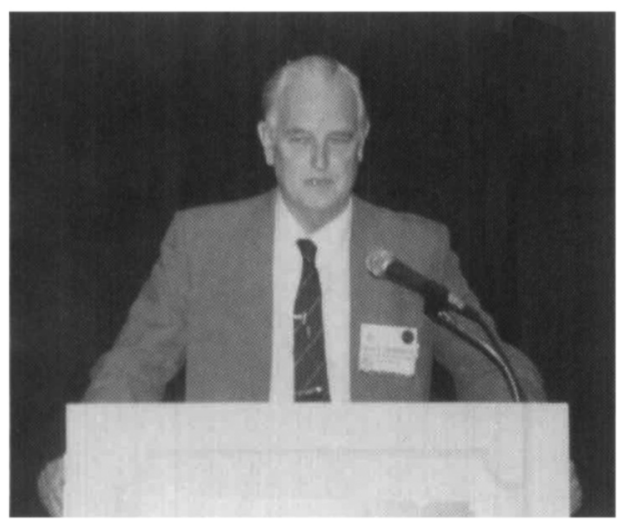

A. Chynoweth (Bell Communications Research), Chair of MSE Study Panel 2.

\section{MSE Study Panel 2}

Alan Chynoweth, Chair of Panel 2 on Exploitation of MSE Technology for $\mathrm{Na}$ tional Welfare, then described that panel's mission. He pointed out that "something is not working as well as it should in the innovation process" and that this issue must be addressed because it is essential to U.S. economic strength. Chynoweth, from Bell Communications Research, is well qualified to provide an overview in this area. Noting that technology transfer is central to linkages within the R\&D network, he named four readily identifiable links: (1) traditional publications, meetings, and conferences; (2) accidental serendipitous interactions which often depend on such mundane factors as the design of the building housing the researchers; (3) deliberate mechanisms for information transfer; and (4) other generally weak links between R\&D manufacturers and marketers. He identified scientific curiosity and engineering needs as intermal forces which act positively. One internal force which inhibits progress he characterized as the "notinvented-here" syndrome, referring to attitudes within the institution and the individual. He then listed 28 ixternal forces which impact the linkages in R\&D and indicated that the re were several omissions he had noticed. These external forces ranged from political issues such as national pride to trends in industry such as multinational corporations to issues of education, export constraints, national policy, public ignorance of R\&D, competition, regulatory agencies, government subsidies, environmental questions, and many more.

Chynoweth cited the need to identify those nodes in the process where a "critical mass" of effort needs to be applied. Such nodes he said, include, on the local level, the materials research laboratories at universities; at the interfacial level, the industry, university or government-industry joint consortia; and at the collective level, consortia among industries and new kinds of entities such as Bell Communications Research with seven operating companies involved in its ownership and direction. He also cited the need for a long-range vision and the need to have that vision articulated by government without governmental attempts to direct its implementation. He challenged professional societies particularly, saying that "they might be more visible/audible rather than making selfserving noises concerning their own little part of the action."

Indicating that research and development need added momentum, Chynoweth explained that "momentum" is defined as a mass times a time derivative of position, and concluded that a "critical mass" is needed with the proper direction and the proper speed of implementation in order to make progress.

\section{MSE Study Panel 3}

Lyle Schwartz of the National Bureau of Standards and Chair of Panel No. 3 on Internationa! Cooperation and Competition in MSE detailed the panel's mission and activities. Its mission, he said, includes a quantitative assessment of international MSE activity, determination of the differences and similarities to MSE in the United States, comparison of U.S. national MSE policies and strategies with those abroad, and an assessment of the role of MSE in ind ustrial competition, particularly in relation to multinational entitites. The panel is taking three approaches, he continued, first probing the existing literature for statistics and program information. Second, the panel is circulating a questionnaire to a representative set of foreign countries which pursue MSE. Third, the panel will consider case studies on the intent and scope of research in particular cases covering such areas as structural materials in commercial aircraft, steel manufacturing, information/communication materials, ceramic heat engines, engineering plastics, and possibly zeolites as catalysts. Panel 3 will also study features of technology transfer in the foreign country context.

Schwartz noted that the United States has experienced difficulty in "harvesting information" from international competitors. This is apparently becoming more

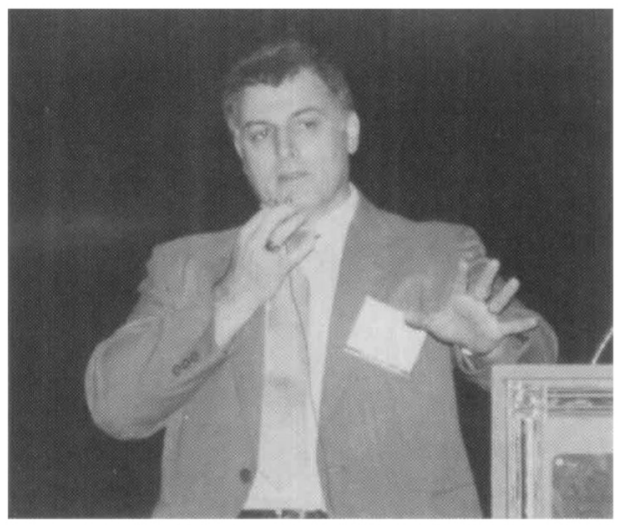

L. Schwartz (NBS), Chair of MSE Study Panel 3. difficult now than in the past. Citing statistical evidence for this trend, he said that over the past decade travel by U.S. scientists to foreign meetings has decreased $45 \%$. During the following discussion with the audience, it was suggested that the countries to be surveyed include those regarded as"supplier nations" even though they don't explicitly pursue MSE, and that environmental issues relevant to a worldwide materials cycle might be included in this panel's charter.

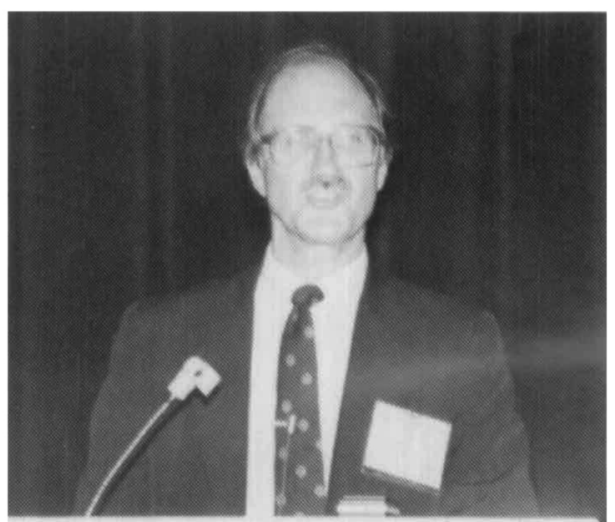

T. Loucks (Norton Company), Chair of MSE Study Panel 4.

\section{MSE Study Panel 4}

Chair Terry Loucks of the Norton Company said that the task of Panel 4 on Research Resources in MSE is to assess present resources (both physical and human) available to MSE and to forecast future requirements. This panel, he said, is particularly interested in building a concensus around these issues and in providing opportunities for all constituencies to be heard. Remarking that "more and more people are calling themselves materials scientists and engineers, not all the time, but certainly at funding time," Loucks said he expects a good deal of interest because the results of this panel's survey may impact the next federal budget. Panel 4 has been subdivided into subpanels-federal research laboratories, large research facilities, intermediate scale research facilities, individual principal investigators, advanced instrumentation, structural materials, and electronic materials-all actively garnering information.

\section{MSE Study Panel 5}

Panel 5 Chair Professor l.M. Bernstein of Carnegie-Mellon University was the final speaker. In explaining the goals of Panel 5 on Education in MSE, Bernstein presented statistics on trends over the past several years for students from various disciplines entering materials-related fields and graduating at different degree levels. This issue is complex because the boundary between the discipline and the materials categorization is not clear. For example, he said, those working in polymers have stopped calling themselves chemists and starting

Continued 


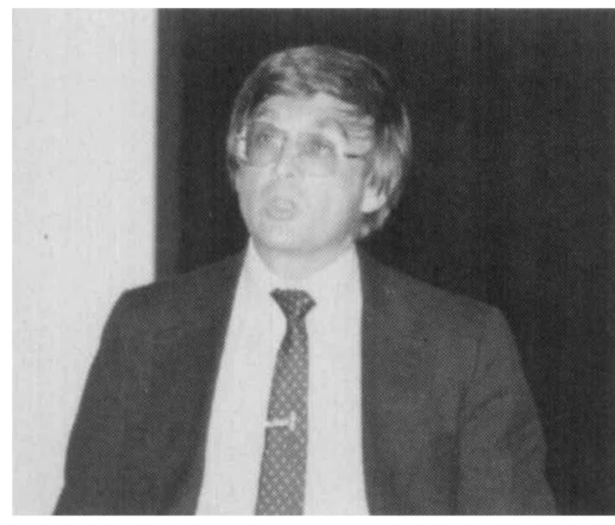

I.M. Bernstein (Carnegie-Mellon University), Chair of MSE Study Panel 5.

calling themselves materials scientists to some extent.

Bernstein identified four task categories which the panel will pursue. The first involves a study of the disciplines which offer materials programs, and will include a study of the pool of students and their demographics, including students coming from abroad. In addition, a forecast of the need for the educational product, i.e., students in academia, industry, government or nonprofit laboratories, will be attempted. A second task, called "future directions of education in MSE," deals with issues such as curricula, accreditation, engineering/science "tilt," and similar ones. The third task is to identify the needs and opportunities for increasing interdisciplinarity in MSE education. Bernstein commented that this seems easier in graduate research than in the undergraduate schools. The fourth task is to examine the needs and opportunities in lifelong or continuing education. Following Bernstein's presentation a member of the audience observed that the Panel 5 members seemed to over-represent universities and under-represent the education's customer, which is industry.

The spokesman for each panel solicited audience input and announced a desire for suggestions and comments from as wide a spectrum of materials science and engineering constituencies as possible. The time scale tentatively set for each panel would produce rough drafts of the panel reports in April 1987. A forum to discuss the MSE Study is currently being planned for March 1987 at NAS/NAE.

Another opportunity for the materials community to provide input for and hear about progress concerning the MSE Study is during the Materials Research Society's Forum on the Materials Science and Engineering Study at the 1986 MRS Fall Meeting in Boston. A report on the MRS Forum will be published in the next issue of the BULLETIN.

\section{Subscribe to}

\section{MATERIALS LETTERS}

At Special MRS Member Rates

I am a member of the Materials Research Society and wish to subscribe to the following volumes of Materials Letters at the special MRS member personal subscription rate.

Check appropriate volume(s):

Volume IV (current volume) $\$ 17.50$

$\$$

Volume V \$ \$20.00

$\$$

Volume Vl $\$ 20.00$

$\$$

TOTAL ENCLOSED

$\$$

Name

Organization

Address

City

State

Zip/Postal Code

\section{Country}

Return subscription order with payment to: Materials Letters Subscription, Materials Research Society, 9800 McKnight Road, Suite 327, Pittsburgh, PA 15237; telephone (412) 367-3012 


\title{
THE METALLURGICAL SOCIETY PRESENTS ...
}

\author{
proceedings of the \\ 1986 TMS Northeast Regional Meeting \\ held at AT\&T Bell Laboratories \\ in Murray Hill, New Jersey \\ Co-sponsored by the \\ Materials Research Society
}

....An essential volume for materials scientists involved in electronic materials, this volume focuses on the structure and stability of interfaces in a variety of semiconductor-based device structures.

The contents address the increasingly important role that heterostructures will play in future microelectronic devices. Emphasis is placed on the materials science aspects of semiconductor-semiconductor, semiconductor-insulator, and semiconductormetal interfaces.

TOPIC AREAS INCLUDE:

- Strained Layer Superlattices (SLS) including structure, stability, growth, and prediction of stability of SLS structures

- Silicon on Insulators - including a review of $\mathrm{SOI}$ technology, covering such diverse technologies as $\mathrm{CaF}_{2}$ on $\mathrm{Si}$, Si on $\mathrm{Al}_{2} \mathrm{O}_{3}$, Si on $\mathrm{ZrO}_{2}$, and deep oxygen implant technology (SIMOX) process

- Perfection of Epitaxial Silicides highlighting methods of preparing substrates for epitaxial deposition and analysis of defects generated at growth interfaces
- Metallization and Passivation of III-V Compounds - including a review of current work in III-V compound passivation, metal-III-IV interactions, and the nature and complexity of interfacial reactions.

Edited by M.L. Green, J.E.E. Baglin, G.Y. Chin; H. Deckman, W. Mayo and D. Narasinham.

465 pp. ISBN: 0-87339-056-3

\section{MRS MEMBER PRICE: $\$ 50$ LIST PRICE: $\$ 73$}

Order from:

Publications Department

Materials Research Society

9800 McKnight Road, Suite 327 Pittsburgh, PA 15237

Telephone (412) 367-3012

Prepayment required. VISA and Mastercard accepted. 


\section{FROM PLENUM: A COMPOSITE OF THE LATEST RESEARCH}

A new series...

\section{MICRODEVICES : Physics and Fabrication Technologies}

Series Editors: Ivor Brodie and Julius J. Muray

\section{GaAs DEVICES AND CIRCUITS}

by Michael Shur

This book is intended for the rapidly growing GaAs community of researchers and graduate students. Based on courses developed and taught at the University of Minnesota, Shur's work covers the structure, properties, and technology of GaAs devices and circuits.

CONTENTS: Chemical bonds and crystal structure. Band structure and transport properties. GaAs technology. Ridley-Watkins-HilsumGunn effect. Transferred electron oscillators. Transferred electron amplifiers and logic and functional devices. GaAs FETs - device physics and modeling. GaAs FET amplifiers and microwave monolithic integrated circuits. GaAs digital integrated circuits. Modulation doped field effect transistors. Novel GaAs devices. Index.

0-306-42192-5/657 pp. + index/ill. $/ 1986 / \$ 75.00$

text adoption price on orders of six or more copies: $\$ 39.50$
Forthcoming.

\section{SEMICONDUCTOR}

LITHOGRAPHY

Principles, Processes, and Materials

by Wayne M. Moreau

Moreau's comprehensive reference on micron lithography details basic resist materials, the lithographic processes, and the fundamental principles behind each process. Every process step and resist composition is covered. Moreau discusses the progress of resist material improvements and explains how lithographic problems have been solved.

CONTENTS: Introduction. Positive photoresists. Positive radiation resists. Negative photoresists. Negative radiation resists. Surface preparation and coatings. Prebake. Optical exposure. Radiation exposure. Developing resist images. Postbake. Additive processes. Subtractive etching. Stripping of resists. Process control. Nonresist processes. Index.

0-306-42185-2/975 pp./ill./1987

\section{NONMETALLIC MATERIALS AND COMPOSITES AT LOW TEMPERATURES 3}

\section{edited by Günther Hartwig and David Evans}

The third volume in this series contains the findings of international researchers investigating polymers, glasses, MDF cements, rubber, organic insulators, resins, and fiber composites. Studies document the mechanical properties, thermal conductivity, interlaminar shear strength, and performance at low temperature of the various materials examined. A volume in the Cryogenic Materials Series.

0-306-42117-8/proceedings/232 pp./ill./1986/\$49.50

- refrigeration materials

- mechanical properties

- physical properties

- nondestructive evaluation

- materials and devices for superconducting electronics

- superconducting nitride films

- fine filamentary superconductors

- superconductors - AC losses

- radiation damage and flux pinning in superconductors

- multifilamentary $\mathrm{Nb}_{3} \mathrm{Sn}$ superconductors

- new superconducting materials and methods

0-306-42292-1/proceedings/1,140 pp./ill./1986/\$110.00

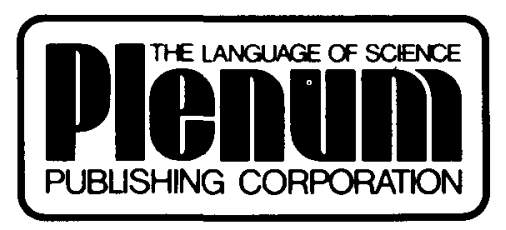

Plenum Publishing Corporation 233 Spring Street

New York, N.Y. 10013-1578 